\title{
Research and Application on Information Resources Planning for University
}

\author{
Hong Lin, Yajuan Sun \\ Network and Information Center \\ North China Electric Power University \\ Beijing, China \\ syj@ncepu.edu.cn
}

\author{
Baohui Wang \\ School of Software \\ Beijing University of Aeronautics and Astronautics \\ Beijing, China \\ wangbh@ncepu.edu.cn
}

\begin{abstract}
Information resource planning is a bridge for information technology planning and implementation, which plays a connecting role. This paper discusses the basic principles and methods of information resources planning. Taking University Information Resource Planning as example, this paper introduces the business process analysis, requirements analysis, business modeling and system modeling of the University core business processes, at last proposes the reference model for practical application from practice.
\end{abstract}

Keywords-Information Resource planning; requirements analysis; system modeling

\section{INTRODUCTION}

With the continuous development of education informationization, the process of informatization of Higher Education in China are mostly in the stage of system integration, the construction of information system is turning from department-level into the university-level. Top-level design, unified planning, unified standards, data concentration and systems integration, are the main tasks of the university informatization. The nature of the university informatization is to do the whole process transformation and management innovation by using IT and analyzing the overall university business, which is the complex and high risk system engineering. Generally, with the proposal of career development planning, the university will formulate the information development plan which can be short-term, medium-term, or long-term planning. Such planning is mainly to solve the "what to do", not directly to guide the implementation for informatization, which need the information resource planning ,that is, on the basis of the university information system planning, to do the planning of the information systems and information technology, and finally to implement the specific data planning of the university, moreover, to plan a rational technical architecture, and to finish the design of the blueprint for university informatization. Information resource planning is the bridge of informatization planning and implementation, which plays a connecting role to resolve the problem of "how to do" for the university informatization, is the indispensable work to guarantee the healthy and sustainable development of the university informatization.

\section{THE BASIC PRINCIPLES OF INFORMATION RESOURCE PLANNING}

\section{A. the definition of information resource planning}

Information Resource Planning (referred to as IRP), refers to the comprehensive planning, including collection, processing, transmission to the usage, for the information that the governments or enterprises need,. It is the overall planning focusing on analysis of data, to integrate information resources, to eliminate islands of information and to achieve the sharing of information resources [1].

Information resource planning can be briefly described as "five criteria, three models, and two stages". Five criteria are: data element standard, information classification coding standard, standard user view standards, concept database standards and logical database standards; three models are: system function model, system data model, system architecture model; two stages are: requirements analysis phase and system modeling phase.

\section{B. The method of information resource planning}

The requirements analysis is the first stage of the information resource planning, the main process is [2]: According to the goals of the informatization implementation of the organization, delineating the boundaries of information systems, analyzing the business processes and data of every function domains in the organization, defining the flow and process of the information by drawing business processes diagrams and data flow diagrams, and determining the business model. The requirements analysis workflow is shown in Fig. 1, including the functional requirements analysis and data requirements analysis.

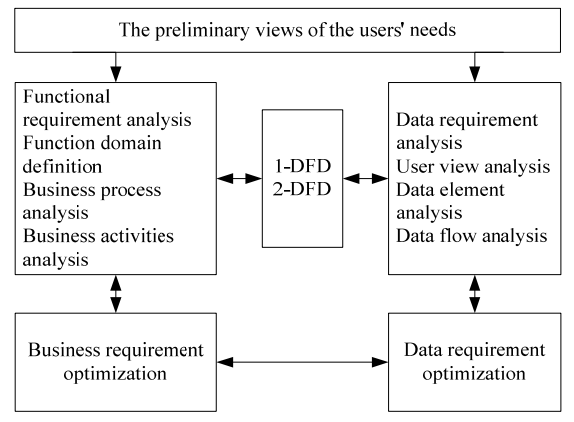

Figure 1. the requirements analysis workflow 
In the analysis of functional requirements, the main work is: business research, business process analysis, and formation of the business model; in the analysis of data requirements, the main work is: Standardizing user view, analyzing data from the source, and data flow analysis. The results of requirements analysis is prepared for the system modeling.

With the results of the requirement analysis, the issues to be considered is: how to define the system functions and data requirements so as to meet the innovation needs of the current business management; how to conduct scientific selection, how to determine the development order and the data distribution; how to constrain the behavior of developers in the process of system development. The work of system modeling is to implement the above problems into a model, to standardize and restrict the detailed design and development work of the system. System modeling includes the following three parts, i.e. the system function modeling, system data modeling and system architecture modeling.

The key points in the system modeling process are: a) subsystem idea, informatization feasibility analysis, and function modeling; b) subject databases idea, data model, data modeling, architecture modeling, and data standards optimization. The main results of the system modeling are: function model, data model, architecture model, information resources management basis standards.

From the business model to the function model, the main analysis work is to conduct informatization feasibility analysis for the business processes and business activities, and to establish the function model for the business processes and business activities that can be processed by computer or human-computer interaction.

System data modeling is a core part of the information resource planning, which emphasizes the overall strategic data planning to establish the highly shared subject database. The data modeling process is shown in Fig. 2, first identifying and defining the business subjects, grouping and dividing the user views into large entities group by subjects, establishing the conceptual data model; then proceeding to the standardization of data structures, and further analyzing the properties of the entities according to business needs, standardizing data structure to generate the basic tables, establishing the logical data model; at last standardizing data element, further examining the composition of the base tables, implementing the data element standards and information classification codes to the basic table.

$$
\begin{array}{ccc}
\text { User view(document } & \text { Data } & \text { Data } \\
\text { and report) } & \text { model(concept) } & \text { model(logical) }
\end{array}
$$

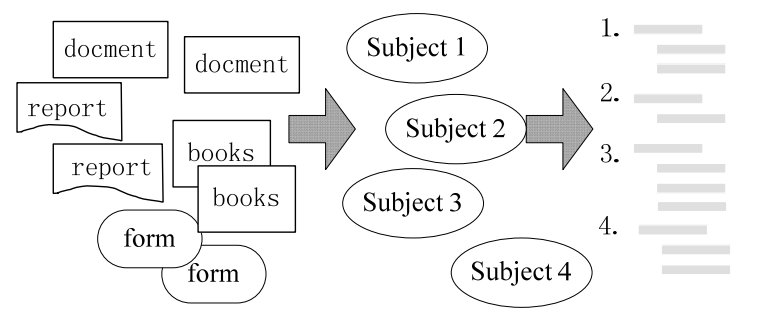

Figure 2. data modeling process
The system architecture modeling, is the process to build the relational structure between the data model and function model, is the scientific basis of determining the responsibility of the creation and use of the sharing database, and of analyzing data distribution and formulating system development plan [3]. In the planning project, the system architecture modeling needs the support of the appropriate software tools to form the C-U matrix model.

\section{APPLICATION AND IMPLEMENTATION OF INFORMATION RESOURCE PLANNING FOR UNIVERSITY}

\section{A. The requirements analysis}

The requirements analysis includes the strategic requirements analysis and the business requirements analysis. The strategic requirements analysis is sourced from the development strategy and informatization development strategy, is obtained by the decomposition and abstraction of the two strategies, is the source and the basis of university information resources planning. Strategic requirements analysis workflow is shown in Fig. 3.

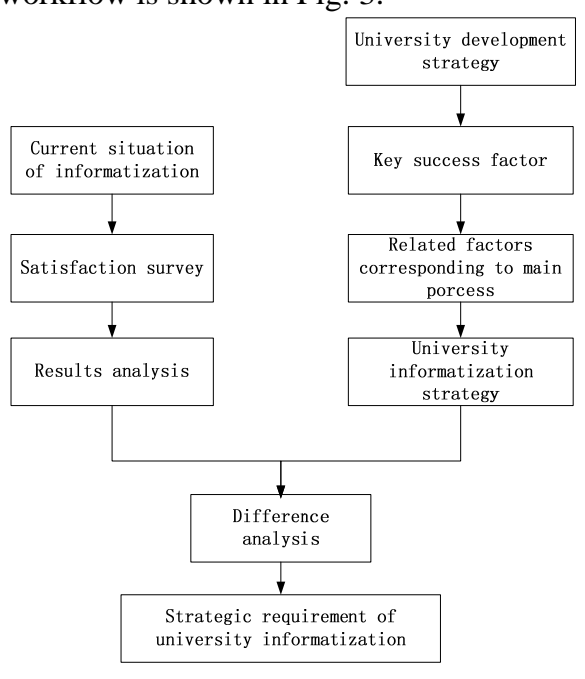

Figure 3. strategic requirements analysis of the basic workflow

1) Business process analysis. Business requirements analysis firstly conducts the business process analysis based on the strategic needs of the university informatization. University business are very complicated, business process analysis may not be exhaustive, which should take the university core business as the main line and start from the following three aspects: a) the core business class, i.e. the personnel training and scientific research business covered in the university, including teaching and management of undergraduate and graduate, the management mentioned here include teaching management, it should also include the management about enrollment and employment, another core business is university research scientific management; b) management and supporting business class, which is all management and service business expanding around the core business, including office management, financial management, human resources management, asset 
management, party management, archives management, library management and medical management; c) Strategic decision class, this type of business does not correspond to the daily operations, but serves for the strategic positioning of university. It provides services for the subject construction, teacher development, and scientific research strategy and enrollment plan.

General comprehensive university need to analyze 100150 core business processes.

2) Functional requirements analysis. The main functional requirements analysis, include function domain division, business process definition, business activities definition. Function domain is not a replica of the institutional sector in the university, but it should cover all institutional sectors, usually one function domain corresponds to one or more of the institutional sectors. The function domain has stability and industry characteristics, which is the abstract of the business. The general comprehensive university can be divided into about 10 function domains by analyzing the range of functions of the organization in university.

Business process refers to a set of closely relating management activities, which is refinement and standardization of business processes analysis. Comprehensive university can be defined approximately 260 business process, and 2700 business activities from 10 function domains, and ultimately the university's business model will be generated. The example of business models is shown as TABLE I.

TABLE I. UNIVERSITY BUSINESS MODEL EXAMPLE

\begin{tabular}{|c|c|c|}
\hline $\begin{array}{l}\text { Function } \\
\text { domain }\end{array}$ & $\begin{array}{l}\text { business } \\
\text { process }\end{array}$ & business activities \\
\hline \multirow{13}{*}{$\begin{array}{l}\text { Undergraduate } \\
\text { education and } \\
\text { teaching } \\
\text { management }\end{array}$} & \multirow{6}{*}{$\begin{array}{l}\text { teaching task } \\
\text { management }\end{array}$} & $\begin{array}{l}\text { develop the work plan of the } \\
\text { entire school year }\end{array}$ \\
\hline & & $\begin{array}{l}\begin{array}{l}\text { issue teaching task allocation } \\
\text { tables }\end{array} \\
\end{array}$ \\
\hline & & Appoint the teachers \\
\hline & & The teachers test teach \\
\hline & & $\begin{array}{l}\text { Fill in the task of teaching } \\
\text { allocation table }\end{array}$ \\
\hline & & ..... \\
\hline & \multirow{6}{*}{$\begin{array}{l}\text { course } \\
\text { arrangement }\end{array}$} & $\begin{array}{lll}\begin{array}{l}\text { Summarize the teaching tasks } \\
\text { allocation table of every } \\
\text { departments }\end{array} & & \\
\end{array}$ \\
\hline & & $\begin{array}{l}\text { Inquire teaching institutions } \\
\text { information }\end{array}$ \\
\hline & & Inquire classroom usage \\
\hline & & Inquire teachers' information \\
\hline & & $\begin{array}{lll}\text { set priority level of course } \\
\text { arrangement }\end{array}$ \\
\hline & & $\ldots \ldots$ \\
\hline & $\ldots \ldots$ & $\ldots \ldots$ \\
\hline
\end{tabular}

3) Data requirements analysis. The main work of the data requirements analysis starting from the analysis of the user view, it includes: the classification and registration of the user view, the composition of the user view, the standardized expression of the user view, data flow analysis and standardization of data elements. The data requirements analysis results are the basis of the system data modeling.
Generally about 2800 user views and 3000 data elements can be generated for a comprehensive university.

The user views involved in the daily management of the university include: input forms, printed reports, updated screen data formats, and query screen data format. The work about user view analysis can be carried out in accordance with the following four steps: a) Analyzing all the user views of each business activity according to the business activities; b) classifying and coding the user view; c) completing the composition of the user views by registering each of the data elements in the user views; d) normalizing expression of the data structures of the user views following the paradigm theory, typically expressed as $1 \mathrm{NF}$.

For example, in the business process of enrollment management, we need 11 user views. User view registration is shown in TABLE II.

TABLE II. USERS VIEW REGISTRATION FOR ENROLLMENT MANAGEMENT BUSINESS PROCESS EXAMPLE

\begin{tabular}{|l|l|l|}
\hline No. & $\begin{array}{l}\text { User view } \\
\text { symbol }\end{array}$ & User view name \\
\hline 1 & D053301 & enrollment schedule for every provinces \\
\hline 2 & D051301 & candidates basic information table \\
\hline 3 & D051302 & $\begin{array}{l}\text { candidates scores table of college } \\
\text { entrance examination }\end{array}$ \\
\hline 4 & D053302 & candidates admitted table \\
\hline 5 & D052301 & Student number compiling table \\
\hline 6 & D052302 & placement information table \\
\hline$\ldots \ldots$ & $\ldots \ldots$ & $\ldots \ldots$ \\
\hline
\end{tabular}

The data flow analysis is one work of the data requirements analysis, which is the auxiliary of the later data modeling. The data flow here is the flow of the user views, the 1-level data flow diagram starts from the height of the whole school, comprehensively observes each function domain, combines some function domains by data flow, and get the general knowledge about university from requirements analysis aspect. The 2-level data flow diagram is a record of further investigation for the business process and data requirements in a certain function domain, it is mainly used for the guidance of the identification and definition of business processes, as well as the definition and standardization for storage-type user view. Due to limited space, this paper will not expand the description.

\section{B. System Modeling}

The requirements analysis is the preparation for the system modeling, which is the continuation and "shaping" of the requirements analysis. System modeling includes the system function modeling, data modeling and system architecture modeling.

1) System function modeling. According to the 10 function domains divided by requirements analysis, through the function requirements analysis, the function model can be built on the basis of the business model. The final university information system should include the 9 subsystems, which are decision support subsystem, collaborative office subsystem, human resources subsystem, financial management subsystem, asset management subsystem, Undergraduate education and teaching management subsystem, graduate management subsystem, scientific 
research management subsystem, logistics management subsystem.

To define subsystem's function modules, that is decomposing the objectives of the subsystem and implementing to the specific function modules. To define the program module on the basis of above, which is the smallest processing unit of the program, which is defined as two types of business activities automated or human-computer interacted according to their computerized feasibility analysis.

Comprehensive university need to define about 300 function modules, and 3000 program modules.

2) System Data Modeling. Based on the business model produced by functional requirements analysis and the results of data requirements analysis, according to the correlation of business, analyzing the relationship between the user views, and dividing close-knit user views together to form a large group of users view, in which the user views are closely linked within these large user view groups, and less contact with the external user view. Each large user view group is a business subject, which can be defined as the subject database. Subject database is corresponding to the business, having similar business in the same areas. The number of subject databases defined is approximately similar, and about 40 subject databases are defined in a comprehensive university.

Subject databases are designed according to database design method after determining the business subject. Firstly the concept subject databases are created, and then the logical subject databases are created after the further decomposition and refinement of the concept subject databases. In the relation mode of the data organization, the logical database is a set of standardized tables.

3) System architecture modeling. Information System Architecture refers to the correlation structure of the system data model and function model, which solves the problem creating and using for databases, which is expressed using the C-U matrix. The system architecture model's building is the basis of determining the responsibility of the creation and use of the shared database, conducting the analysis of data distribution and the developing the system development program. The system architecture model is divided into the global system architecture model and the subsystem architecture model. The global system architecture model is expressed as the global C-U matrix, which indicates the correlation between all the subsystems and the subject databases. Subsystem architecture model is expressed as subsystem C-U matrix, which indicates the correlation between all function modules and the base tables in one certain subsystem. The global system architecture model is shown as Fig. 4.

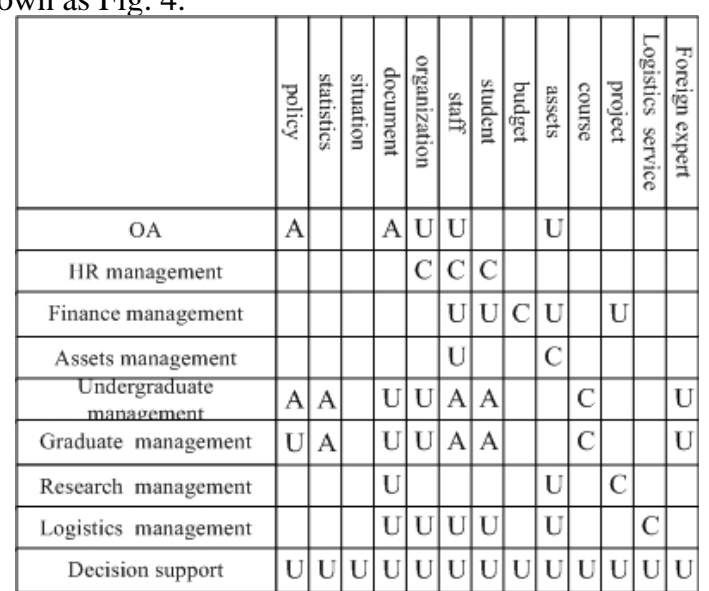

Figure 4. the global system architecture model(section)

\section{CONCULSION}

University informatization is a complex and arduous task. As the basis of the information construction project, information resources planning should be of more concern and attention, it is also necessary to study and master the correct methodology. As the premise and basis of the information systems design and implementation for university, information resources planning can avoid the occurrences lack of overall ideas like "do only what you think of; correct only the problems found clearly", ensure the smoothly circulating and sharing of information among all the departments of the university, eliminate problem caused by information islands, and support universities to improve their core competitiveness in striving for world-class universities.

\section{REFERENCES}

[1] F.X. Gao. Information Resource Planning - information foundation construction engineering, Beijing: Tsinghua University Press, 2002, pp.78.

[2] N.N. Yao, Y.S. Fan.Information resource planning practice research, manufacturing automation, Vol 28, 2006, pp.96-98.

[3] S.L. Ge. "Enterprise Information Model Research”, East China Shipbuilding Institute (Natural Science), 2001, vol. 6. 